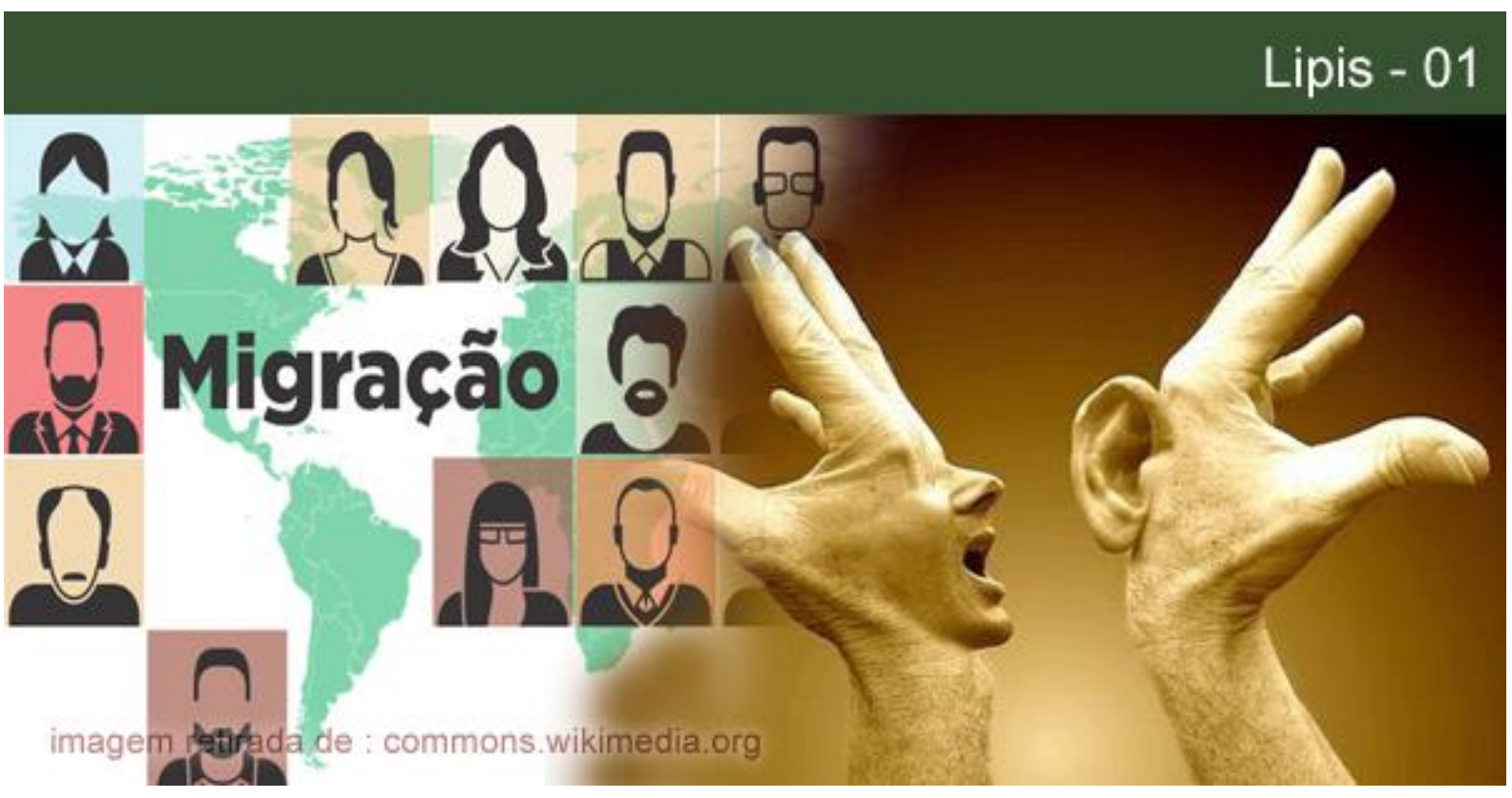

\title{
MIGRAÇÃO, PESQUISA BIOGRÁFICA E COMUNIZAÇÃO DE EXPERIÊNCIAS DE VIDA
}

\author{
Lúcia Ozório \\ Pesquisadora laboratório Experice, França - universidades Paris 8 e Paris 13-Nord); Laboratório Lipis - \\ Laboratório Interdisciplinar de Pesquisa e Intervenção Social, PUC. Membro do GT Psicologia Comunitária - \\ Anpepp. Membro de L'AMAP - França - Associação dos Povos do Mundo. E-mail: lozorio@gmail.com.
}

Resumo: Refletimos sobre a problemática comunitária e o processo migratório, quer dizer, sobre as alianças deste processo com a construção de um comum no mundo. A experiência de mobilidade precisa ser compreendida desde as experiências de vida, perspectiva que dá importância ao encontro dialógico com os atores deste processo. As histórias orais de vida em comum, nosso dispositivo de pesquisa e de resistência, aprofundam nossas reflexões. Como dispositivo da biopolítica tem como chave de ouro a produção de subjetividades que busca responder às urgências de um comum no presente. Buscamos apostar no potencial revolucionário da memória nas suas conexões com o comum, reservatório de heterogêneses, intervindo numa memória sequestrada e sobrecodificada que quer silenciar as diferenças. Este trabalho no campo imanente da memória permite o surgimento das potências revolucionárias de afetos imemoriais que convocam experiências de liberação, contribuindo para a reconstrução de si e de um comum no mundo, produzindo subjetividades. Palavras-chave: Processo migratório. Comum. Histórias orais de vida em comum. Subjetividades.

\section{MIGRATION, BIOGRAPHIC RESEARCH AND COMMUNIZATION OF LIFE EXPERIENCES.}

Abstract: We reflect on the community issues and the migration process, that is, on the alliances of this process with the construction of a common in the world. The experience of mobility needs to be understood from life experiences, a perspective that gives importance to the dialogical encounter with the actors of this process. The oral life stories in common as a research device, of resistance, allows to deepen this perspective. As a device of biopolitics, it has as a golden key the production of subjectivities that seeks to respond to the urgencies of a common in the present. We seek to bet on the revolutionary potential of memory in its connections with the common, reservoir of heterogenesis, seeking to intervene in a kidnapped and overcoded memory that wants to silence the differences. Work with the immanent field of memory permeated by the common allows the emergence of the revolutionary powers of immemorial affections that call for liberation experiences, contributing to the reconstruction of oneself and of a common in the world, producing subjectivities.

\section{POLÊM!CA | LABORE ( (3)}

Polêmica - Revista Eletrônica da Uerj - Rua São Francisco Xavier, 524, $1^{\circ}$ andar bloco D, sl.1001 • Tels.: +55 21 2334-4088/4087 • http://www.e-publicacoes.uerj.br/index.php/polemica/index http://www.labore.uerj.br • laboreuerj@yahoo.com.br 
Keywords: Migrationprocess. Common. Oral lifestories in common. Subjectivities.

\section{Introdução}

[...] A minha situação é bem próxima desta história. Minha bisavó veio para cá no navio negreiro. Aliás, não é uma história tão distante do que vivemos hoje em dia. O que acontecia na época? Eles iam pra Vassouras, saíam daqui do porto do Rio pra Vassouras; de lá eles iam sendo distribuídos pelas fazendas. E minha bisavó foi distribuída lá em Vassouras, para umas fazendas; lembro-me de uma, São Luiz da Boa Sorte. De lá, ela veio para a fazenda de Ubá, onde se casou. Minha avó nasceu nesta fazenda e veio pequenininha para a fazenda do Guarani, onde mais tarde minha mãe e eu nascemos. Depois a gente veio para Mangueira. (...)

Essa cumplicidade é que fortalece, nos seríamos dizimados com certeza sem isso aí. O poder público, não está nem aí pra gente, não fazem nada, nada, nada ... Escrevi alguma coisa sobre o que chamei de Os novos navios negreiros. Mais de 100 anos se passaram e o problema continua, a escravização dos povos. (...)antes as pessoas eram pegas à força e colocadas em navios empilhadas como se fossem coisas, objeto. Hoje é o mesmo empilhamento, só que as pessoas, obrigadas pelas péssimas condições de vida nos seus países, pagam para sair deles, se submetendo à viagem quase sempre sem destino, para lugares desconhecidos. Com um pouco de sorte esses escravos conseguem firmar-se e construir uma nova pátria. Muitas vezes são mandados de volta, ou morrem de fome, miséria, doenças sem que o processo de libertação lhes seja apresentado. .(...) (SILVINA apud OZORIO, 2016, p. 133-134)

Esse texto tenta contribuir para os debates sobre imigração nas ciências sociais. O processo migratório traz uma provocação: como fazer para que se possa reinventar novas coordenadas de enunciação face a uma globalização como perda de mundo, como imundo, inmundo, imundialização, como diz Nancy (2002), dando formas a subjetividades que se aliem às urgências de um comum no presente? (OZÓRIO, 2014; 2016).

Começamos com um fragmento da história de vida de Silvina, moradora de Mangueira, favela também conhecida como comunidade e/ou morro da Mangueira, no Rio de Janeiro, Brasil. A história de Silvina, bisneta do processo de escravização com que Portugal violentou o Brasil, foi narrada durante a pesquisa que realizamos com a Mangueira desde 2003. Nesta pesquisa contamos com apoio de convênio entre a Universidade do Estado do Rio de Janeiro (UERJ) e a Fundação Carlos Chagas de Amparo à Pesquisa do Estado do Rio de Janeiro (FAPERJ) (2003-2004; 2005- 2006; 2010-2012); do laboratório Experice (Centro de Pesquisa em Educação Habilité, Paris 8 - Paris 13) das universidades Paris 8 e Paris 13, França (2007 - atual); do Laboratório Interdisciplinar de Pesquisa e Intervenção Social (LIPIS) - PUC - Rio de Janeiro (2007 - atual); e de L'AMAP - França - Associação dos Povos do Mundo (2008-atual) (OZÓRIO, 2005; 2007; 2008; 2014; 2016).

\section{POLÊM!CA $\mid$ LABORE}

Polêmica - Revista Eletrônica da Uerj - Rua São Francisco Xavier, 524, $1^{\circ}$ andar

bloco D, sl.1001 • Tels.: +55 21 2334-4088/4087 • http://www.e-publicacoes.uerj.br/index.php/polemica/index http://www.labore.uerj.br • laboreuerj@yahoo.com.br 
Com a história de Silvina podemos estabelecer relações entre a problemática comunitária e o processo migratório, quer dizer, sobre as alianças deste processo com a construção de um comum no mundo. O Estado - este um - não se adequa ao nomadismo do comum, que quer uma escrita voltada para o porvir (NEGRI, 2006; OZÓRIO, 2016). Consideramos as comunidades pobres como um lugar singular de construção do comum, reservatório de heterogênese, como lugar em que um processo migratório está na sua potência sempre se fazendo. São muitas migrações: de corpos, de sonhos, de desejos, de subjetividades; de deuses, lembrando Amir Baraka quando diz que os africanos vieram para a América acompanhados dos seus deuses; de histórias de vidas - dizem Mangueira e Silvina. Estas comunidades se apresentam como outros lugares, heterotopias, para os que vivem o mar revolto da diáspora cultural e política atravessada por um cenário distópico e contemporâneo em que desigualdades e violências sustentam o privilégio de poucos e requerem a miséria de muitos.

Pensamos que nas ciências sociais precisamos analisar a migração do ponto de vista dos imigrantes. Mais precisamente, a experiência de mobilidade precisa ser compreendida desde as experiências de vida - perspectiva que leva em conta necessariamente um encontro dialógico com os atores deste processo migratório. Lembrando Benjamin (2000), as "histórias surpreendentes" estão escassas. Estamos saturados do autoritarismo da informação, como diz Santos (1998).

As histórias orais de vida em comum, nosso dispositivo de pesquisa, aprofundam nossas reflexões. Com este dispositivo temos acesso às experimentações de vidas únicas e narradas coletivamente, dando visibilidade não só a uma diversidade de modos de ser, estar, agir e se mover no mundo, como também às intensidades e afetos que perpassam este experienciar. Temos a problematização da vida que se inventa. Captamos esta invenção nas histórias narradas em comum. A experiência migratória é analisada a partir dos que vivem este processo.

Os moradores da comunidade da Mangueira inventaram o Papo de Roda, espaçotempo para contar em comum as suas histórias. No Papo de Roda, os sonhos construídos com pedaços emprestados "de lá e de cá", os exílios que habitam cada um dos narradores, com suas intensidades, potências e dilaceramentos vão cadenciando uma história que intervém na etnologia da solidão, como diz Augé (2005). A memória comum, que se constrói, provoca em

\section{POLÊM!CA $\mid$ LABORE}


cada um dos participantes a sensação de que sua história atravessa a História e que esta inclui aquela.

Buscamos com esse dispositivo nos aliar aos moradores da Mangueira, narradores das histórias, no sentido de buscar construir junto com estes uma comunidade de destino, lembrando Jacques Loew (1959), em Jornal de uma missão operária, quando diz que é preciso experimentar uma comunidade de destino para ter uma compreensão de uma certa condição humana. Assim, nesta pesquisa, narradores e pesquisadora se abrem a uma experimentação comum: se consideram como co-construtores do mesmo mundo, da mesma sociedade como contexto de significações sempre em jogo.

Nossa utopia, construída quotidianamente significa ter entre nós, um olhar de igualdade, sabendo das nossas diferenças e das grandes desigualdades que atravessam as vidas dos moradores das comunidades pobres, inclusive, da Mangueira. A história oral de vida em comum como dispositivo de resistência busca captar a potência das experiências migratórias que pulsam através dos tempos, mostrando a atualidade da história oral de vida na sua importância para o século XXI, parafraseando Portelli (2000).

Pensamos que os mais indicados para falar das experiências migratórias são os que passaram de algum modo por esta experiência. Muitos estudos sobre imigração não fogem à regra de muitos outros na área das ciências sociais (ALTHABE, 2002), tomando os imigrantes como objeto de análise. Somos contrários à esta posição. Optamos por abrir vias em que como sujeitos, os autores da experiência narrativa possam favorecer cartografias de suas experiências para que possam migrar pelo mundo e ... devir. A experiência migratória vai contagiando outros cantos, transmitindo o ímpeto por longas distâncias, de maneira imprevisível, nas velocidades próprias do tempo comunitário, o tempo dos pobres.

\section{A história oral de vida em comum, dispositivo biográfico aliado de processos migratórios}

G. Deleuze (2003), ao interrogar a noção de dispositivo utilizada por M. Foucault, diz que nós pertencemos a dispositivos e neles agimos. Ressaltamos que a utilização do nosso dispositivo história oral de vida em comum é uma estratégia de resistência, o que implica encontrar uma alternativa para cada solução que emerge, uma abertura às potências constituintes de todo campo de trabalho (OZÓRIO, 2016).

\section{POLÊM!CA $\mid$ LABORE}


Importante relevar a história oral como primeiro momento da nossa pesquisa biográfica. Nela percebemos a sabedoria africana, bastante presente na Mangueira, que confirma sua importância no dizer de HampatéBá: quando um velho morre uma biblioteca se queima.

Moradores da Mangueira desejam afirmar suas histórias de vida e buscam alianças com essa pesquisa num momento difícil que atravessava suas vidas em 2003: a intolerância do programa Tolerância Zero do Estado do Rio de Janeiro que marcava apenas sua tolerância com as desigualdades sociais. Os moradores da Mangueira querem que suas histórias andem ao redor do mundo, que não se queimem. Como diz Celso dos Reis, um morador desta comunidade:

\footnotetext{
Vamos fazer um Papo de Roda. O Idoso conta sua história para o jovem para que este conte a sua "[...]"A gente vai contar as histórias das rezadeiras, das criadoras de porco, das verdureiras (.....).A Mangueira está precisando disso. Pessoal pensa que Mangueira é escola de samba ou marginalidade. Tem no meio disso aí toda a comunidade, que ninguém conhece [...]" (OZÓRIO, 2016, p. 31).
}

Interessante relevar que a Mangueira encontra um modo bastante singular de responder/resistir ao programa intolerante do Estado, que queria exterminar as insurgências comunitárias face às violências que sofriam. A Mangueira migra para o mundo com suas histórias de vida em comum (OZÓRIO, 2016).

A estratégia de resistência escolhida pela comunidade da Mangueira foi dar primazia à história de suas vidas, contadas num primeiro momento, oralmente. Com isto, seus jovens vão crescer rodeados de histórias, parafraseando Conceição Evaristo (2006) quando diz que nasceu rodeada por palavras.

Mercedes Vilanova (2003) disse em um artigo recente que uma memória viva, felizmente, é sempre uma memória conflitiva. Ao colocar os jovens em contato direto com, como diz Celso, os idosos, a Mangueira mantém a memória de sua criação e de sua ancestralidade trabalhando o passado como ficção do presente e o presente como força viva do socius. Trata-se de memória que se vai construindo - intervindo na separação que o capital faz entre as gerações, ao criar um fosso entre as dobras necessárias deste encontro.

A narração em comum, no Papo de Roda, como campo privilegiado da memória, dá a esta uma qualidade de inquietação. Como diz Ozório (2007; 2016), trata-se de experiência que constrói uma memória comum, que não nega as tensões do convívio com as diferenças, que

\section{POLÊM!CA $\mid$ LABORE}


transborda a experiência individual, desdobrando suas consequências e suas virtualidades, inclusive de perturbação.

Se há uma dimensão subjetiva da experiência que escapa à pura objetividade, há também a práxis de sua hibridização pelo comum que se faz no momento da narração, mostrando que este como experiência pode funcionar como designação liberadora, não substancial.

Se as histórias de vida são, como diz Pineau (2012), uma arte formadora de existência, elas participam também de uma dimensão de invenção do outro. O processo de narração hibridizado pelo comum, lida com a imprevisibilidade, a partir das conexões entre as diferenças em jogo no processo narrativo, assumem sua potência na tensão de se lembrar-agir em comum. Estamos no seio essencialmente problemático da memória, no qual uma memória coalescente com o presente é engendrada e se deixa levar nas suas linhas de fuga. Busca-se assim enfrentar riscos de um certo enclausuramento da memória no sujeito ou nos grupos.

O Papo de Roda trabalha no campo da imanência da memória pelas vias do comum. Nosso dispositivo traz uma inquietação: como apostar no potencial revolucionário da memória nas suas conexões com o comum?

A história de vida em comum como estratégia de subjetivação política enfrenta tensões com a problemática ao mesmo tempo ontológica e política de produzir memória, ao buscar intervir numa memória sequestrada e sobrecodificada que quer silenciar as diferenças, controlar as experiências migratórias no mundo. O trabalho com a memória ontológica permite o surgimento das potências revolucionárias dos afetos imemoriais que se intensificam nas mais diversas dobraduras de experiências de vidas que ali se convocam e se abrem às experiências de liberação, contribuindo para a reconstrução de si e do mundo ao seu redor, produzindo subjetividades.

As situações de marginalidade, de precaridadde, de sofrimento, de escravização, mas de muita potência - resistência que permeiam a história de Silvina contada no Papo de Roda para os jovens de Mangueira desperta-nos para um universo em que uma comunhão de vozes dos que viveram e vivem a violência dos navios negreiros clama por um revigoramento de forças, resistem e tentam tecer a solidariedade. Mangueira é Angola antiga com seus gritos e sussurros que migram nas histórias de vida como a contada por Silvina, deixando claro que não há espaço para o emudecimento.

\section{POLÊM!CA $\mid$ LABORE}


A novidade do nosso dispositivo história oral de vida em comum é o atual que ele porta. O atual é o nosso devir-outro. Nos dispositivos há o que somos, isto é, o que já deixamos de ser - a parte da história - e no que estamos nos tornando - a parte do atual (OZORIO, 2016, p. 61; DELEUZE, 2003, p. 322).

\section{O comum, este novo amor e o biográfico}

As histórias de vida nas suas diversas formas e funções são produzidas em contextos sociohistóricos e permitem debates sobre seus atravessamentos sociais e políticos (DELORYMOMBERGER; NIEWIADOMSKY, 2009).

Nesta imundialização consideramos as histórias de vida como um ato de subjetivação política. Como tal, apresentam modos de resistir ao capitalismo global reforçando experiências de cooperação e invenção (NEGRI, 2011; OZORIO, 2014; 2016).

Consideramos a história oral de vida em comum um dispositivo da biopolítica, na qual a chave de ouro é a produção de subjetividades. Como diz Guattari (2009, p. 129), a subjetividade

... é cada vez mais manufaturada em escala mundial... deparamo-nos com um outro fenômeno, justamente ligado a esta mundialização da produção da subjetividade e sua crescente integração de todas as funções humanas e máquinas, o que eu chamei de Capitalismo Mundial (CMI).

A produção de subjetividades é campo de potências em que um jogo de tensões desenha linhas de liberdade e dominação. O capital consome a subjetividade, consome a vida. Mas há a própria vida que virou um capital, como diz Negri, que se constitui como um novo "valor de uso" no interior do poder (NEGRI, 2006, p. 35). Importante relevar como o faz Negri que a passagem do moderno para o pós-moderno é marcada não apenas pela submissão ao capital, mas pela construção de uma resistência desde seu interior. O autor restabelece a determinação ontológica da resistência já que, paradoxalmente, nesta circulação de poder, processos de subjetivação, de resistência e insubordinação podem acontecer. Novos modos de ser, estar, sentir, novas inteligências e novas ternuras podem se engendrar.

A história de vida em comum dos migrantes como dispositivo de produção de subjetividade é presença de um sopro comum que revigora, mas também uma espécie de tempestade que agita existências. Comunhão de vozes se convocam e provocam. A subjetividade essencialmente social e assumida, vivida pelo migrante, nas suas existências particulares, tem diversos processos semióticos que a atravessam. A narração de histórias de

\section{POLÊM!CA $\mid$ LABORE}


vida trabalha de modo original certos modos de resistir na contemporaneidade, dando visibilidade à potência das diferenças que portam elementos criativos, fundamentais na produção da subjetividade.

Em Commonwealth, Hardt e Negri (2013) contribuem de modo enriquecedor para esta discussão, quando relevam a produção de elementos criativos na produção do comum, como processo mutante de diferenças que se agenciam e engendram novos modos de ser, estar e agir no mundo. É provocador pensar o comum como reservatório de heterogênese, intervindo em entendimentos do comum como homogeneidade. É instigante se pensar o comum, processo mutante de diferenças que se convocam, que convidam a pensar no cuidadoinsistência que se deve ter na sua construção como potência animada pelas diferenças.

Hardt e Negri (2013) consideram que o amor é uma produção de elementos criativos do comum. Acham o amor um conceito essencial para a política e a filosofia. E o que conta no amor “...é a produção de subjetividade e o encontro de singularidades que compõem novos agrupamentos e constituem novas formas do comum" (HARDT; NEGRI, 2013, p. 274).

Pensamos que este novo amor, o comum, é essencial para o biográfico (OZORIO, 2016). O comum, como forma de amor revolucionário, supõe a alteridade. Engendra a resistência neste mundo vampirizado pelo capital estimulador do culto ao mesmo e do individualismo que o reproduz. Seu tecido heterogêneo, pluri-referenciado, maquina a reinvenção de novos modos de subjetivação.

Tal compreensão do amor, como produção de elementos criativos do comum e suas formas de cooperação e invenção, porta uma crítica às formas corrompidas do amor identitário, do amor aprisionado pela propriedade privada, pela família e pelo fetichismo da mercadoria. O Estado, suas inteligibilidades e desigualdades é posto em questão. Pode-se compreender o comum como um modo de reaprender o mundo segundo o registro da criação?

O dispositivo história de vida em comum permite um aprofundamnto desta perspectiva, abrindo reflexões sobre o processo migratório como praxis do comum no mundo. Os que vivem a experiência migratória ao comunizar suas histórias não só fazem uma crítica em ato ao silenciamento das diferenças, mas mostram resistências-potências que trabalham na produção de novas subjetividades no mundo. Uma cultura da diferença animada pela resistência prolifera explorando a potência da experiência narrativa em suas cartografias,

\section{POLÊM!CA $\mid$ LABORE}


mostrando que a produção de subjetividade, uma produção cultural, guarda uma relação íntima com o biográfico.

G. Deleuze acha importante "acreditar no mundo",

... suscitar acontecimentos mesmo pequenos, ou fazer nascer novos espaços-tempos, mesmo que de superfície ou de volumes reduzidos, (...). É ao nível de cada tentativa que se julga a capacidade de resistência ou ao contrário a submissão ao controle. (DELEUZE, 2003, p. 239).

O Papo de Roda é um espaço-tempo de narração de histórias de vida que nasce na comunidade da Mangueira. Faz alianças com uma história implicada com as urgências do comum no mundo. Afinal, se a história é a que escolhemos (VEYNE, 1992), se escolhemos uma história que leva em conta o comum, buscamos fazer frente ao historicismo que “...mobiliza uma massa de fatos para preencher um tempo homogêneo e vazio." (BENJAMIN, 2000, p. 441). Esta história, construída em comum, dá à experiência de vida a importância que tem na prática social. A história do tempo presente, dos agoras (BENJAMIN, 2000; VEYNE, 1992), exercita o agorismo, trazendo para a praça pública muitas visões de mundo. E relevamos: trata-se de uma história sem pretensões de se erigir em verdade, forjando o comum, outro espaço-tempo na política. Afinal, são tantos mundos de vidas, não é?

\section{REFERÊNCIAS}

ALTHABE, Gerald. Oppression et libération dans l'imaginaire - Les communautés villageoises de la côte orientale de Madagascar. Paris: La Découverte, 2002.

AUGÉ, Marc. Não lugares: introdução a uma antropologia da sobremodernidade. $1^{\text {a }}$ edição francesa. Lisboa: 90 Graus, [1992] 2005.

BARAKA Amir. Some body BlewUp America \& other poems. House of Nehesi Publishers. Philipsburg, St. Martin, Caribbean, 2003.

BENJAMIN, Walter. Oeuvres III. Paris: Gallimard, 2000.

DELEUZE, Gilles. Deux Régimes de Fous. Paris: LesEditions de Minuit, 2003.

DELORY-MOMBERGER Chistine; NIEWIADOMSKY, Christophe. Vivre/Survivre, Récits de résistance. Paris: Téraèdre, 2009.

EVARISTO, Conceição. Becos da memória. Belo Horizonte: Mazza, 2006.

GUATTARI, Felix. Les années d'hiver: 1980-1985. Paris: Les prairies ordinaires, 2009.

LOEW, Jacques. Journal d’une mission ouvrière. Paris: Ed. Du Cerf, 1959.

\section{POLÊM!CA $\mid$ LABORE}

Polêmica - Revista Eletrônica da Uerj - Rua São Francisco Xavier, 524, $1^{\circ}$ andar

bloco D, sl.1001 • Tels.: +55 21 2334-4088/4087 • http://www.e-publicacoes.uerj.br/index.php/polemica/index

http://www.labore.uerj.br • laboreuerj@yahoo.com.br 
NANCY, Jean.- Luc. La création du monde ou la mondialisation. Paris: Galilée, 2002.

NEGRI, Toni. Fabrique de porcelaine. Paris: Editions Stock, 2006.

La construction du commun: un nouveau communisme. In: BADIOU, A.; ZIZEK S. L'Idée du Communisme. France: Nouvelles Editions Lignes, p. 199-214, 2011.

NEGRI, Toni; HARDT, Michel. Commonwealth. Paris: Gallimard, 2013.

OZORIO, Lucia. Perspectivas da pesquisa comunitária: Comunidade como práxis e seus diálogos com as histórias orais de vida. Revista Estudos e Pesquisas em Psicologia. v. 7, n.1, p. 28-41, 2017.

As pipas da cidade. Pistas - história de comunidade. Revista Polêmica, v 7, n. 4, out/dez, 2008. Disponível em: < www.polemica.uerj.br.>.

Novas texturas do mundo: modos de pensar o comum In: Maciel, T. B.; D’Ávila M. I. N.; ANDRADE, R. G. N. Diversidades Culturais: desafios para o reconhecimento no estado global. Rio de Janeiro: MauadFaperj, p. 47-58, 2012.

Penser Les Périphéries. Une expérience Brésilienne. Pourun nouveau type de politique publique de construction du commun. Paris: L'Harmattan, 2014.

. La favela de Mangueira et ses histoires de vies en commun. Travailler avec les periphéries. Paris: L’Harmattan, 2016.

Por uma nova compreensão de cidade: o poder comum de agir e as histórias de vida de Mangueira. Revista Lugar Comum, n. 49, 2017.

PINEAU Gaston; MARIE-MICHÈLE. Produire sa vie: autoformation et autobiographie. Paris: Téraèdre, 2012.

PORTELLI, Alexandro. Memória e diálogo: desafios da história oral para a ideologia do século XXI. In: FERREIRA, M. M.; FERNANDES, T. M.; ALBERTI, V. (Orgs.) - História Oral: desafios para o século XXI. Rio de Janeiro: Fiocruz/Casa de Oswaldo Cruz/FGV, p. 67-71, 2000.

SANTOS, Milton. Técnica, espaço, tempo - Globalização e meio técnico-científico informacional. 4. Ed. São Paulo: Hucitec, 1998.

SCHMIDT, Benito Bisso. Construindo biografias. Historiadores e jornalistas: aproximações e afastamentos. Revista Estudos Históricos, v. 10, nº.19, 1997.

VEYNE, Paul. Comment on écrit l'histoire. Paris: Seuil, 1979.

VILANOVA, Mercedes. Rememoración en la historia. Historia antropologia y fuentes orales. Memória rerum. n. 30, 3ª́poca, p. $23-40,2003$.

Recebido em: 01/02/2018.

Aceito em: 02/03/2018.

\section{POLÊM!CA $\mid$ LABORE}

Polêmica - Revista Eletrônica da Uerj - Rua São Francisco Xavier, 524, $1^{\circ}$ andar

bloco D, sl.1001 • Tels.: +55 21 2334-4088/4087 • http://www.e-publicacoes.uerj.br/index.php/polemica/index

http://www.labore.uerj.br • laboreuerj@yahoo.com.br 